\title{
Effect of co-existing ions on lead leaching behaviour from hardened cement paste
}

\author{
Takumi Nishiwaki ${ }^{1}$, Shaojun Zhou ${ }^{1}$, Masaharu Yamasaki ${ }^{1}$, Yuko Ogawa ${ }^{1}$, Kenji Kawai ${ }^{1}{ }^{\text {,* }}$ \\ ${ }^{1}$ Department of Civil and Environmental Engineering, Hiroshima University, Higashihiroshima, \\ Japan
}

\begin{abstract}
Recently, in the concrete field, the use of industrial wastes for concrete materials is expected for environmental reasons. However, these wastes may contain hazardous heavy metals. It is well known that cement paste has an ability to fix heavy metal ions, whereas it was also found that absorbed heavy metal ions can easily leach from cement paste in the presence of a $\mathrm{CaCl}_{2}$ solution. The present study aims to investigate the lead leaching behaviours from hardened cement pastes in various chloride solutions by tank leaching tests. The water-to-cement ratios of the cement paste specimens were 0.40 and 0.55 . Lead was added to the cement pastes at 1 mass $\%$ of cement. Each chloride solution for the tank leaching test had three kinds of concentrations $(5 \%, 10 \%$, and $20 \%)$. After the tank leaching tests, the chemical changes of the specimens were analysed to discuss the effect of co-existing ions in the solutions. The results indicate that the cumulative lead leaching amount is related to the types of chloride solution as well as the concentrations of the solutions. The lead leaching amount in the $\mathrm{CaCl}_{2}$ solution was much higher than that in other solutions.
\end{abstract}

\section{Introduction}

Recently, a recycling-oriented society is required to solve environmental issues. In the concrete field, the use of industrial wastes for concrete materials is expected. However, these wastes may contain hazardous heavy metals, which makes it difficult to reuse concrete containing industrial wastes. To put the use of concrete containing heavy metals into practice, it is necessary to evaluate the safety of heavy metals in concrete.

A previous study shows that cement paste has an ability to fix heavy metal ions [1]. On the other hand, it is also found that absorbed heavy metal ions can easily leach from cement paste in the presence of $\mathrm{CaCl}_{2}$ solution [2]. It is clear that the leaching of lead is affected by the environment to which the concrete is exposed. Therefore, it is necessary to investigate the leaching of lead in different circumstances. In this study, the leaching behaviours of lead from cement pastes immersed in three kinds of chloride solutions as well as those in deionized water were examined. The influences of every solution to cement pastes were also examined with a thermogravimeter and differential thermal analyser (TG-DTA).

*Corresponding author : kkawai@hiroshima-u.ac.jp 


\section{Experiments}

\subsection{Materials}

In this study, cement paste specimens were prepared. Ordinary Portland cement and deionized water were used as cement and mixing water, respectively. The water to cement ratios $(\mathrm{W} / \mathrm{Cs})$ of the cement pastes were 0.40 and 0.55 . Lead was added to the cement pastes at 1 mass $\%$ of cement. The cubic cement paste specimens of $40 \mathrm{~mm} \times 40 \mathrm{~mm} \times 40 \mathrm{~mm}$ in size were sealed and cured at $20^{\circ} \mathrm{C}$ for 28 days.

\subsection{Tank leaching test}

In this study, tank leaching tests were conducted to clarify the leaching mechanism. Specimens were placed in three kinds of chloride solutions $\left(\mathrm{KCl}, \mathrm{NaCl}, \mathrm{CaCl}_{2}\right)$ as well as deionized water, as shown in Fig. 1. The concentrations of chloride solutions were 5, 10, and $20 \%$ by mass. The volume of the solutions was $480 \mathrm{ml}$ per specimen. The solutions were refreshed at the periods of $0.25,1,2.25,4,9,16,25,36$ and 64 days, and the concentrations of lead in the solutions were determined with an atomic adsorption spectrophotometer.

\subsection{TG-DTA analysis}

The amount of $\mathrm{Ca}(\mathrm{OH})_{2}$ in cement paste in the vicinity of the specimen surface exposed to the solutions was measured with a TG-DTA. The powder samples less than $150 \mu \mathrm{m}$ were obtained at depths of 0 to $0.1 \mathrm{~mm}$ from the surface by grinding the surface of the specimens after 64 days of the leaching test. The sample before the leaching test was also measured.

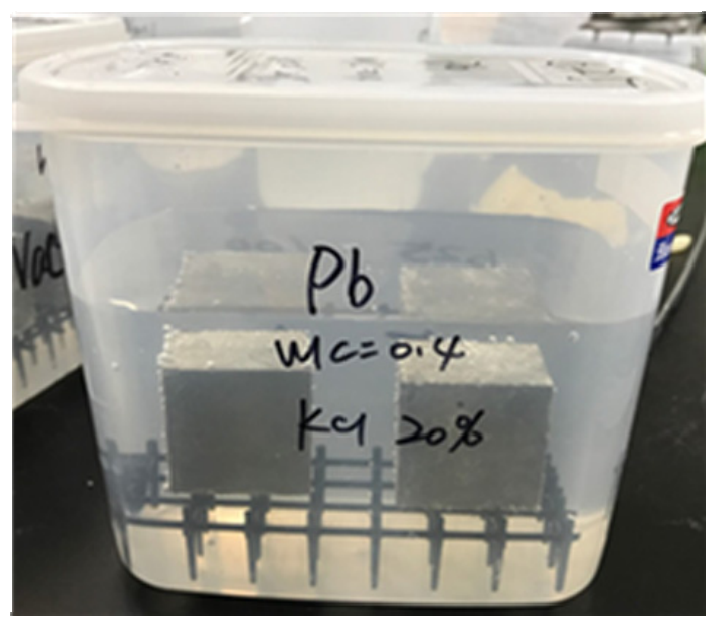

Fig. 1. Tank leaching test. 


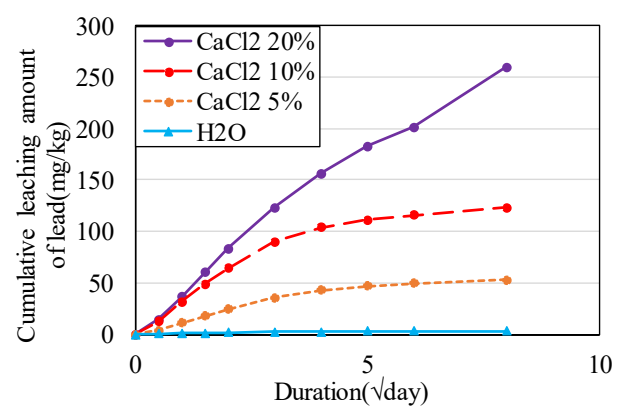

Fig. 2. Cumulative leaching amount of lead from pastes $(\mathrm{W} / \mathrm{C}=0.40)$ immersed in $\mathrm{CaCl}_{2}$ and deionized water for 64 days.

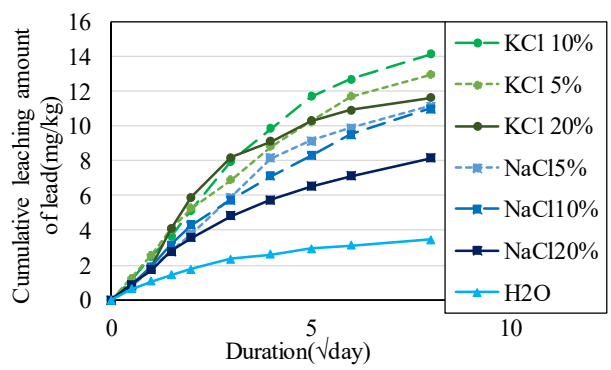

Fig. 4. Cumulative leaching amount of lead from pastes $(\mathrm{W} / \mathrm{C}=0.40)$ immersed in $\mathrm{KCl}, \mathrm{NaCl}$ and deionized water for 64 days.

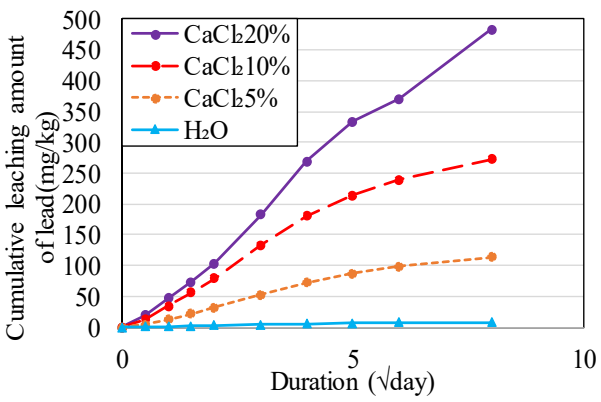

Fig. 3. Cumulative leaching amount of lead from pastes $(\mathrm{W} / \mathrm{C}=0.55)$ immersed in $\mathrm{CaCl}_{2}$ and deionized water for 64 days.

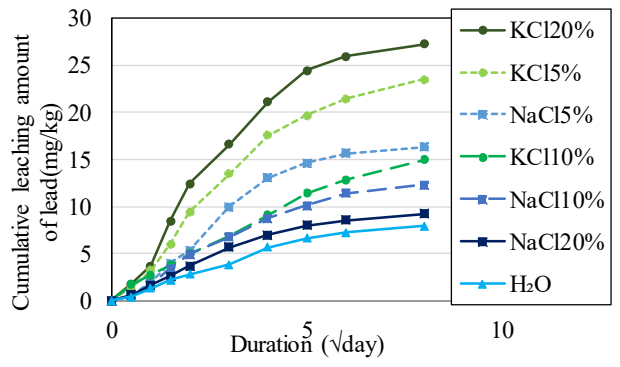

Fig. 5. Cumulative leaching amount of lead from pastes $(\mathrm{W} / \mathrm{C}=0.55)$ immersed in $\mathrm{KCl}, \mathrm{NaCl}$ and deionized water for 64 days.

\section{Results and discussions}

\subsection{Lead leaching amount}

The cumulative leaching amounts of lead from the cement paste specimens with W/Cs of 0.40 and 0.55 immersed in $\mathrm{CaCl}_{2}$ solutions and deionized water for 64 days are shown in Fig. 2 and Fig. 3, respectively. The cumulative leaching amounts of lead from the paste specimens with $\mathrm{W} / \mathrm{Cs}$ of 0.40 and 0.55 immersed in $\mathrm{KCl}$ and $\mathrm{NaCl}$ solutions and deionized water for 64 days are shown in Fig. 4 and Fig. 5, respectively. The value on the vertical axis in the figures represents a leaching amount $(\mathrm{mg})$ per unit mass of the specimen $(\mathrm{kg})$. The results show that the leaching amounts vary in different solutions.

From the figures, the cumulative leaching amount of lead is nearly proportional to the square root of time in every solution. However, the slope of the line changes around 4 to 9 days of immersion. According to Fick's second law, if the cumulative leaching amount of lead is proportional to the square root of time, it can be said that the leaching is governed by diffusion. Therefore, the results imply that the leaching of lead is primarily caused by the diffusion of lead. Additionally, the concentration gradient of lead ions is changed around 4 to 9 days of immersion. Further investigation will be needed to clarify the reason for this. 


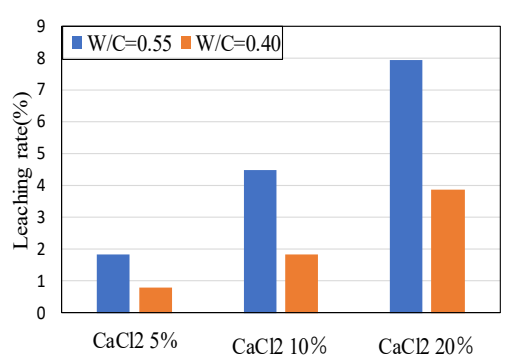

Fig. 6. Leaching rate $\left(\mathrm{CaCl}_{2}\right)$.

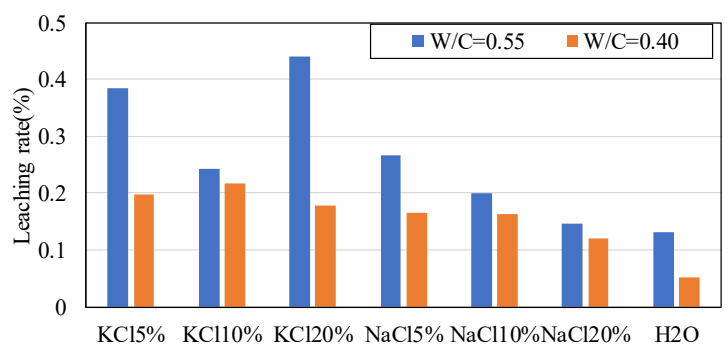

Fig. 7. Leaching rate $(\mathrm{KCl}, \mathrm{NaCl}$, deionized water).

For the leaching amount of lead from the specimens with $\mathrm{W} / \mathrm{C}=0.40$ immersed in every $10 \%$ solutions and deionized water, the largest amount of lead was leached in $\mathrm{CaCl}_{2}$ solutions, followed by $\mathrm{KCl}$ solutions, $\mathrm{NaCl}$ solutions and deionized water. The lead leaching amount in the $10 \%-\mathrm{CaCl}_{2}$ solution was approximately 35 times as much as that in deionized water, which agrees with the previous study [2]. The same tendency can be observed in the specimens with $\mathrm{W} / \mathrm{C}=0.55$.

From the viewpoint of the concentration of chloride solutions, the lead leaching amount was almost proportional to the concentration of the solutions in the case of $\mathrm{CaCl}_{2}$ solutions. On the other hand, the lead leaching amount had no correlation with the concentration of solutions in the case of $\mathrm{KCl}$ solutions and $\mathrm{NaCl}$ solutions, and the differences were small.

Figs. 6 and 7 show the leaching rate of lead, which represents a leaching amount $(\mathrm{mg})$ per lead content (mg). Fig. 6 shows the leaching rate of lead from the specimens immersed in $\mathrm{CaCl}_{2}$ solutions, while Fig. 7 shows the leaching rate in $\mathrm{KCl}$ and $\mathrm{NaCl}$ solutions and deionized water. The leaching rate from the specimens immersed in $20 \%$ of $\mathrm{CaCl}_{2}$ solution were the highest of all solutions. However, even for the specimen with $\mathrm{W} / \mathrm{C}=0.55$ immersed in $20 \%$ of $\mathrm{CaCl}_{2}$ solution which showed the highest value among all specimens, the leaching rate was only $8 \%$, which means that most lead ions dosed in the specimens were still fixed in cement hydrates. The leaching rate for the specimens with $\mathrm{W} / \mathrm{C}=0.40$ is lower than that with $\mathrm{W} / \mathrm{C}=0.55$ in every case. In the case of $\mathrm{CaCl}_{2}$ solutions, the leaching rate of the specimens with $\mathrm{W} / \mathrm{C}=0.55$ is twice as large as that with $\mathrm{W} / \mathrm{C}=0.40$.

\section{$3.2 \mathrm{Ca}(\mathrm{OH})_{2}$ content}

Figs. 8 and 9 show the $\mathrm{Ca}(\mathrm{OH})_{2}$ content in the specimens with $\mathrm{W} / \mathrm{C}=0.40$ and $\mathrm{W} / \mathrm{C}=0.55$, respectively, at 64 days of immersion. The $\mathrm{Ca}(\mathrm{OH})_{2}$ content in the specimen before the leaching test is also shown in the figures. The previous study indicated that $\mathrm{Ca}(\mathrm{OH})_{2}$ has an ability to fix heavy metal ions [1]. Thus, the decrease in the $\mathrm{Ca}(\mathrm{OH})_{2}$ content can cause heavy metal ions to leach out more easily.

According to Fig. 8 for the results in the case of the specimens with $\mathrm{W} / \mathrm{C}=0.40$, the specimen before immersion contained $15.5 \%$ of $\mathrm{Ca}(\mathrm{OH})_{2}$. However, the $\mathrm{Ca}(\mathrm{OH})_{2}$ content of the specimen after immersion in deionized water was $3.6 \%$, and the specimens after immersion in chloride solutions contained $0.8 \%$ to $5.8 \%$ of $\mathrm{Ca}(\mathrm{OH})_{2}$. In both figures (Fig. 8, Fig. 9), the $\mathrm{Ca}(\mathrm{OH})_{2}$ content decreased with the immersion period. Therefore, all specimens could reduce the ability to fix heavy metal ions. 


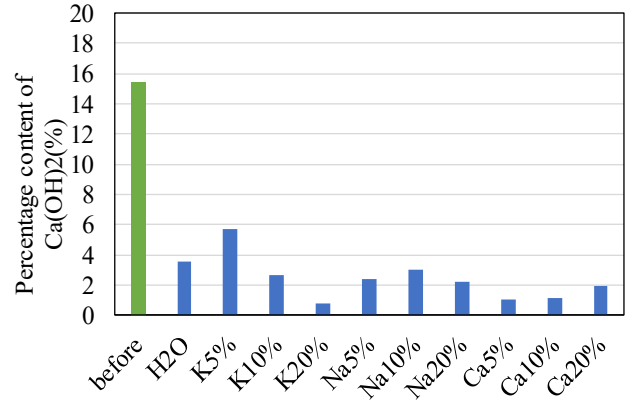

Fig. 8. $\mathrm{Ca}(\mathrm{OH})_{2}$ content in specimens $(\mathrm{W} / \mathrm{C}=0.40)$.

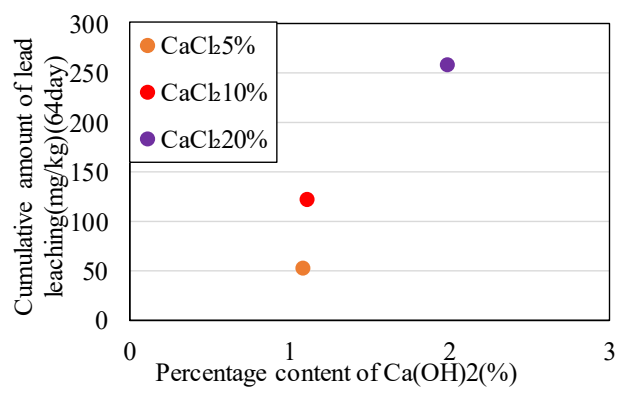

Fig. 10. Relationship between leaching amount and $\mathrm{Ca}(\mathrm{OH})_{2}$ content $\left(\mathrm{CaCl}_{2}\right)(\mathrm{W} / \mathrm{C}=0.40)$.

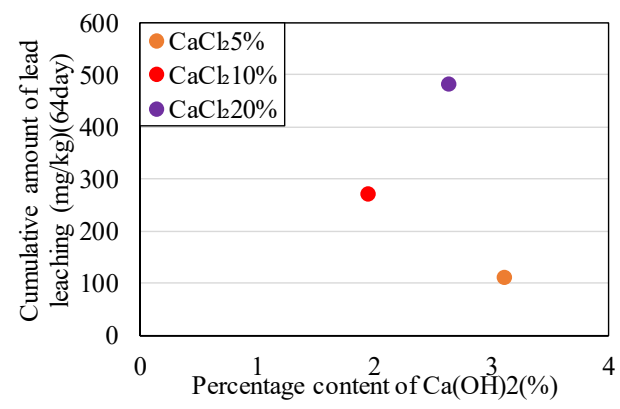

Fig. 12. Relationship between leaching amount and $\mathrm{Ca}(\mathrm{OH})_{2}$ content $\left(\mathrm{CaCl}_{2}\right)(\mathrm{W} / \mathrm{C}=0.55)$.

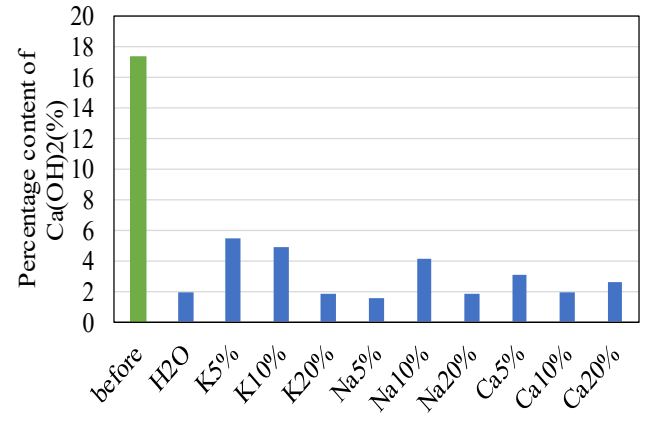

Fig. 9. $\mathrm{Ca}(\mathrm{OH})_{2}$ content in specimens $(\mathrm{W} / \mathrm{C}=0.55)$.

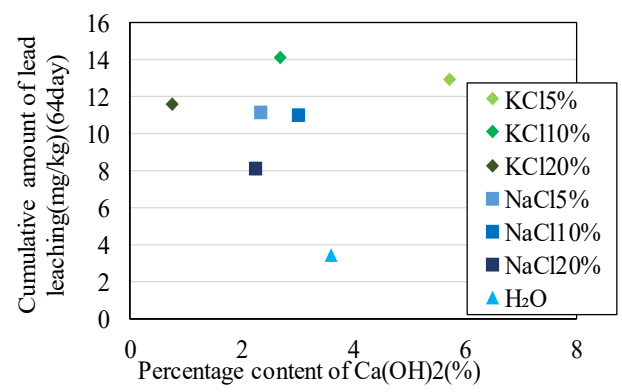

Fig. 11. Relationship between leaching amount and $\mathrm{Ca}(\mathrm{OH})_{2}$ content $(\mathrm{KCl}, \mathrm{NaCl}$, deionized water $)(\mathrm{W} / \mathrm{C}=0.40)$.

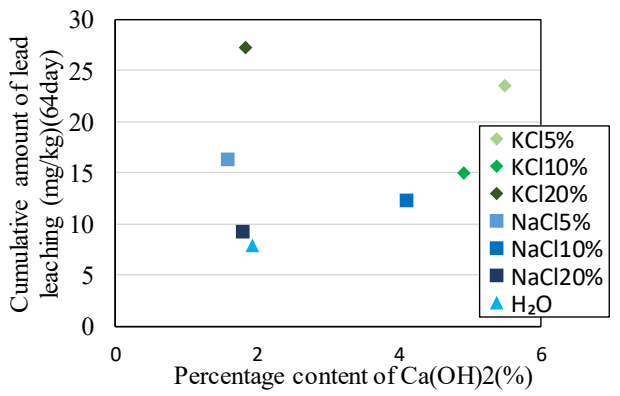

Fig. 13. Relationship between leaching amount and $\mathrm{Ca}(\mathrm{OH})_{2}$ content $(\mathrm{KCl}, \mathrm{NaCl}$, deionized water $)(\mathrm{W} / \mathrm{C}=0.55)$.

Based on Figs. 8 and 9, the difference of the $\mathrm{Ca}(\mathrm{OH})_{2}$ content between the specimens with $\mathrm{W} / \mathrm{C}=0.40$ and $\mathrm{W} / \mathrm{C}=0.55$ before immersion is $1.8 \%$, which is very small compared to the difference of the lead leaching amount between the specimens with $\mathrm{W} / \mathrm{C}=0.40$ and 0.55 . The difference of the lead leaching amount in $\mathrm{W} / \mathrm{C}$ is related to other factors than the difference of the $\mathrm{Ca}(\mathrm{OH})_{2}$ content.

Figs. 10 to 13 show the relationships between the leaching amount and $\mathrm{Ca}(\mathrm{OH})_{2}$ content of the specimens. The results for the specimens with $\mathrm{W} / \mathrm{C}=0.40$ and $\mathrm{W} / \mathrm{C}=0.55$ immersed in $\mathrm{CaCl}_{2}$ solutions are shown in Figs. 10 and 12, respectively, while the results for the specimens with $\mathrm{W} / \mathrm{C}=0.40$ and $\mathrm{W} / \mathrm{C}=0.55$ immersed in $\mathrm{KCl}$ and $\mathrm{NaCl}$ solutions and deionized water are shown in Figs. 11 and 13, respectively. These figures indicate that there 
is no relationship between the cumulative leaching amounts of lead and the $\mathrm{Ca}(\mathrm{OH})_{2}$ content in the specimens after immersion. The difference of the lead leaching amount in the type of solution is also related to other factors than the $\mathrm{Ca}(\mathrm{OH})_{2}$ content in the specimens.

\section{Conclusion}

Within the limits of this study, from the results of the tank leaching test, the largest leaching amount of lead was observed in the $\mathrm{CaCl}_{2}$ solution, followed by the $\mathrm{KCl}$ solution, $\mathrm{NaCl}$ solution and deionized water. In the case of the $\mathrm{CaCl}_{2}$ solution, the lead leaching amount increased as the concentration of the solution increased. However, in the case of the $\mathrm{KCl}$ solution and $\mathrm{NaCl}$ solution, the lead leaching amount was almost the same regardless of the concentration. Based on the results of the $\mathrm{Ca}(\mathrm{OH})_{2}$ content after immersion in the vicinity of the specimen surface exposed to the solution, the difference of the lead leaching amount in the type of solution is not directly related to the $\mathrm{Ca}(\mathrm{OH})_{2}$ content in the specimen after immersion.

\section{References}

1. Kawai, K., Kikuchi, H., Takaya, H., and Hayashi, Cement Science and Concrete Technology, 65, 126-131, (2011)

2. Uchikawa, H, Ceramics, 12, 103-117, (1977) 